\title{
A Cross-Sectional Study of Medication Adherence Pattern and Factors Affecting the Adherence in Chronic Obstructive Pulmonary Disease Shrestha $R,{ }^{1,2}$ Pant $A,{ }^{1,3}$ Shakya Shrestha $S,{ }^{1,2}$ Shrestha $B,{ }^{1,3}$ Gurung RB ${ }^{4}$ Karmacharya BM ${ }^{5}$
}

${ }^{1}$ Department of Pharmacology

School of Medical Sciences, Kathmandu University

${ }^{2}$ Research \& Development Division

Dhulikhel Hospital, Kathmandu University Hospital

${ }^{3}$ Department of Human Biology

Schools of Science \& Medical Sciences

Kathmandu University

${ }^{4}$ Department of Internal Medicine

Dhulikhel Hospital, Kathmandu University Hospital

${ }^{5}$ Department of Community Program

Dhulikhel Hospital, Kathmandu University Hospital

\section{Corresponding Author}

Rajeev Shrestha

Department of Pharmacology

Dhulikhel Hospital, Kathmandu University Hospital

School of Medical Sciences

Kathmandu University

E-mail: rmaleku@hotmail.com

\section{Citation}

Shrestha R, Pant A, Shakya Shrestha S, Shrestha B, Gurung RB, Karmacharya BM. A Cross-Sectional Study of Medication Adherence Pattern and Factors Affecting the Adherence in Chronic Obstructive Pulmonary Disease. Kathmandu Univ Med J 2015;49(1):64-70.

\section{ABSTRACT}

\section{Background}

Chronic obstructive pulmonary disease (COPD) is considered as a major health problem, associated with mortality and morbidities. Various disease management strategies have been established to optimize patient's longevity and functional status where patient adherence to the prescribed treatment plays a key role. Poor adherence to medication is common among COPD patients and is affected by number of factors like number of medicines, delivery devices and patient-related factors.

\section{Objective}

This study aims to investigate the adherence pattern in the management of COPD and factors affecting patient adherence to the prescribed treatment.

\section{Method}

This study is a cross-sectional study which was conducted in a tertiary care hospital. Those patients suffering from COPD of all age were enrolled in this study and prior informed consent was obtained from patients. The structured questionnaire was used to interview those patients.

\section{Result}

Total 100 patients were enrolled in this study, among which most patients $(45 \%)$ were of age groups 60-70 years. Unintentional non-adherence to medication attributed for $65 \%$ of patients and the major reason was forgetfulness (52.3\%). Most patients had discontinued the medication due to experience of side effects (63.3\%). The result showed significant association between adherence and polypharmacy $(p=0.00)$. However, there was no significant association between adherence and age, sex, mode of administration of drugs, technics to use delivery devices etc.

\section{Conclusion}

Majority of COPD patients were elderly (mean age $=68.4$ years). Forgetfulness was associated with medication non-adherence. Most of the patients had discontinued medication because of side effects. Polypharmacy is one of the major factors associated with non-adherence to medication in COPD.

\section{KEY WORDS}

Adherence, COPD, Dhulikhel Hospital, non-adherence, polypharmacy 


\section{INTRODUCTION}

Chronic obstructive pulmonary disease (COPD) is the fourth leading cause of mortality and morbidity worldwide in both industrialized and developing countries which, accounts for $5 \%$ of all death globally. ${ }^{1,2}$ In Nepal, COPD accounts for $43 \%$ of the non-communicable disease burden, and $2.56 \%$ of hospitalizations. ${ }^{3,4}$ Smoking is the main etiological factor to cause COPD followed by occupational dusts, biomass fuels etc. 5

Once the disease is diagnosed, patient education, smoking cessation, pharmacological and non-pharmacological methods are required to ameliorate signs and symptoms of COPD. ${ }^{7,8}$ The pharmacological treatments include bronchodilators, corticosteroids, immunizations, antibiotics, mucokinetics and others. ${ }^{9}$ Failure to the treatment modalities may lead to exacerbations and frequent hospitalizations. Despite the efforts of Global Initiative for Chronic Obstructive Lung Diseases (GOLD) to provide clinicians with the best therapeutic guidance, adherence to pharmacological therapy among patients with COPD has been historically poor and is often the cause of the exacerbations. ${ }^{10}$

Suboptimal adherence in patients with COPD is common due to number of factors such as multiple morbidities, the medication, the delivery device, the patient, and the health professionals caring for the patient. ${ }^{11,12}$ In 2001, the WHO's Adherence Project defines adherence as "the extent to which a person's behavior (taking medication, following a diet, and/or executing lifestyle changes) corresponds with agreed recommendations from a health care provider." ${ }^{13}$ Deviations from medication adherence could be intentional and/or unintentional. Unintentional non-adherence may be due to simple forgetfulness, or inability to follow treatment instructions because of poor understanding or physical problems such as poor eye-sight. ${ }^{14}$ Intentional non-adherence arises when the patient rejects either the doctor's diagnosis or the doctor's recommended treatment, due to experience of side effects or symptomatic relief. ${ }^{14,15}$

Thus, adherence to medication is likely to ameliorate the condition of patients with exacerbation and patients decision to adhere to the prescribed medication depend on their belief about the medications that is intended to treat or prevent the disease. However, very little efforts have been made to explore the role of patient adherence in the management of disease. Therefore, the study aims to investigate the patient adherence and factors affecting it among patients with COPD.

\section{METHODS}

A cross sectional study was conducted in Dhulikhel Hospital, Kathmandu University hospital, Dhulikhel, Kavre after obtaining ethical clearance from Institutional Review Committee, Kathmandu University School of Medical Sciences (IRC approval no. 09/14). Being a tertiary care hospital and one of the referral centers, patients from various part of the country visit this hospital for the treatment. This hospital also has an adequate flow of patients suffering from COPD. Patients of all age group diagnosed with COPD who were admitted from either out-patient department or emergency department were included in the study. However, those patients who were not admitted to the hospital and who do not want to give consent to participate were excluded (Fig. 1).

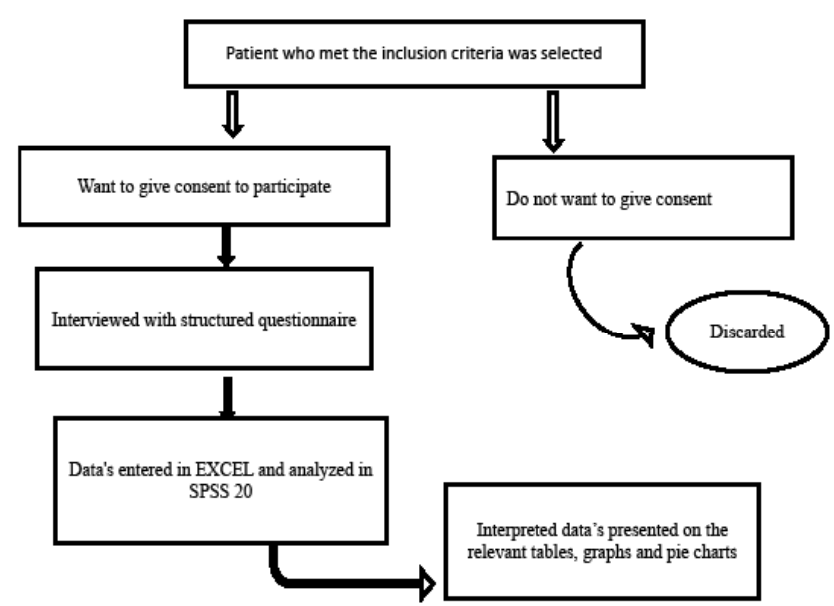

Figure 1. Flowchart showing stepwise procedure of data collection and analysis

Patients who met the inclusion criteria's were informed about the study being done and about their contribution in this study. After taking informed consent from the patients, they were directly interviewed using structured questionnaire. The information regarding age sex, literacy, occupation, smoking/alcohol habit and exposure to any outdoor or indoor air pollution were recorded using the questionnaire. Further questions related to medication adherence like no of medications prescribed per day, reasons for discontinuance, reasons for missing dose, perception about the medication, perceptions about the disease were asked. Additional information about date of diagnosis of COPD, drug treatment for COPD and other concomitant diseases and abnormal clinical findings were recorded from medical case record.

The data collected by using structured questionnaire and reviewing medical record forms were entered in a separate spreadsheet using EXCEL (2010). The entered data was analyzed using Statistical package for social sciences (spss) software version 20. All the quantitative data were expressed as percentage and mean \pm standard deviation (SD) and the qualitative data was analyzed using chisquare test. P-value $<0.05$ was considered as statistically significant.

\section{RESULTS}

Out of hundred-studied cases, majority $(n=63)$ of them were females and the rest $(n=37)$ were male. The mean $( \pm S D)$ age of patients was 68.41 years $( \pm 9.64)$ and most 
patients belong to age group of 60-70 years. More than two thirds of the respondents (82\%) were illiterate and $92 \%$ of them smoked a cigarette for at least two years. Most (68\%) of COPD patients were using both bronchodilators and corticosteroids (Fig. 2).

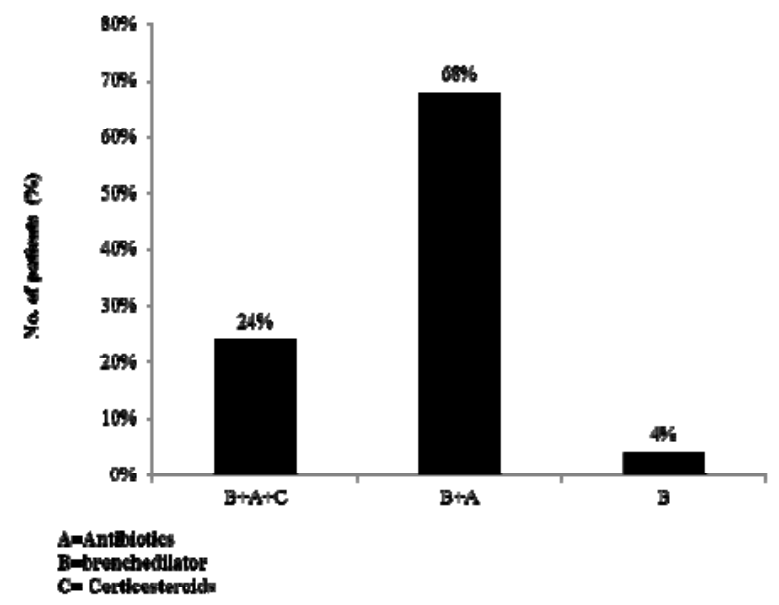

Figure 2. Bar diagram showing drug details among 100 patients

The present study revealed that most patients (65\%) were not adhered to the prescribed treatment (Fig. 3) and the major barrier to adherence was found to be forgetfulness (52.6\%) (Table 1).

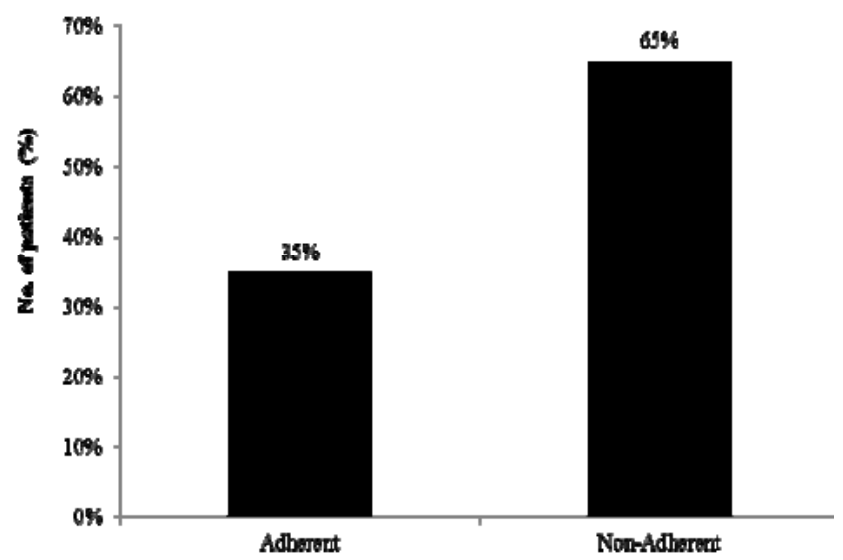

Figure 2. Bar diagram showing adherence pattern among 100 patients

Table 1. Adherence pattern among 100 patients

\begin{tabular}{|l|l|}
\hline Characteristics & No. of patients (\%) \\
\hline $\begin{array}{l}\text { Patient who had missed dose } \\
\text { Reason for missing dose } \\
\mathbf{n}=65\end{array}$ & \\
\hline Forgetfulness & $34(52.3)$ \\
\hline Carelessness & $14(21.53)$ \\
\hline Forgetfulness + Carelessness & $9(13.84)$ \\
\hline Financial problem & $8(12.3)$ \\
\hline Patients who had discontinued dose & $60(60)$ \\
\hline Reason for discontinued $n=60$ & \\
\hline Side effects & $38(63.34)$ \\
\hline Symptomatic relief (lack of clinical symptoms) & $19(31.67)$ \\
\hline Both & $3(5)$ \\
\hline Lack belief & 0 \\
\hline
\end{tabular}

Table 2. Factors affecting adherence among 100 patients

$\begin{array}{llll}\text { Variable } & \begin{array}{l}\text { Total } \\ (\mathrm{n})\end{array} & \begin{array}{l}\text { Adherent* } \\ (\mathrm{n}=65) \\ \text { No.(\%) }\end{array} & \begin{array}{l}\text { Non adherent** } \\ (\mathrm{n}=35) \text { No.(\%) }\end{array}\end{array}$

Route of

administration

\begin{tabular}{lllll} 
Oral & 7 & $1(14.2 \%)$ & $6(85.7)$ & \\
Inhaler & 44 & $16(36.3)$ & $28(63.6)$ & 0.58 \\
Both & 49 & $18(36.7$ & $31(63.2)$ & \\
\hline
\end{tabular}

Proper knowledge

to use inhaler

\begin{tabular}{|lllll|}
\hline Yes & 49 & $20(34.6)$ & $29(65.3)$ & 0.368 \\
\hline No & 44 & $14(38.6)$ & $30(61.3)$ & \\
\hline $\begin{array}{l}\text { Difficult using } \\
\text { inhaler }\end{array}$ & & & & \\
\hline Yes & 26 & $10(38.4)$ & $16(61.5)$ & 0.812 \\
\hline No & 67 & $24(35.8)$ & $43(64.1)$ & \\
\hline
\end{tabular}

No. of medication

( $n=100)$

\begin{tabular}{lllll|}
\hline One & 10 & $9(90)$ & $1(1)$ & 0.000 \\
$\begin{array}{l}\text { Greater or equal } \\
\text { to } 2\end{array}$ & 90 & $26(28.8)$ & $64(71.1)$ & \\
\hline $\begin{array}{l}\text { Education } \\
\text { Illiterate }\end{array}$ & 82 & $20(24.3)$ & $53(64.6)$ & 0.87 \\
\hline Literate & 18 & $6(33.3)$ & $12(66.6)$ & \\
\hline
\end{tabular}

Perception about

disease

\begin{tabular}{lllll} 
Curable & 80 & $30(37.5)$ & $50(62.5)$ & \\
\hline Incurable & 9 & $1(11.1)$ & $8(88.8)$ & 0.32 \\
\hline Only be managed & 11 & $4(36.3)$ & $7(63.6)$ & \\
\hline Family support & & & & \\
\hline Self & 32 & $17(53.1)$ & $15(46.8)$ & 0.009 \\
\hline Family & 68 & $18(26.4)$ & $50(73.5)$ & \\
\hline Medication Costs & & & & \\
\hline Affordable & 83 & $26(31.3)$ & $57(68.6)$ & 0.089 \\
\hline Not affordable & 17 & $9(52.9)$ & $8(47.05)$ & \\
\hline
\end{tabular}

* Patients who had not missed or discontinued medication

**Patients who had missed or discontinued medication

Furthermore, in our study, non-adherence to medication was significantly associated $(p<0.001)$ with polypharmacy and response from the family $(p<0.01 ;$ Table 2$)$. There were, however, no association between adherence and route of administration of drugs, proper knowledge to use inhaler, difficulty using inhaler, medication costs and perception about the disease. Non-adherence (73.33\%) was comparatively higher in patients with age group of 6070 years and less in patients above 70 years of age. Both literate and illiterate patients had missed the dose but frequency was higher for illiterate patients (64.6\%). 


\section{DISCUSSION}

Adherence to medication in patients with COPD is important for optimal management of disease and improved functional status. ${ }^{16}$ Hence, the therapeutic goal of the treatment cannot be achieved till the patient does not adhere to the prescribed medication.

The present study has shown that a greater number (63\%) of females were affected by COPD which was consistent with several studies conducted in Nepal and several other developing countries where women are disproportionately affected. ${ }^{17-19}$ The higher prevalence of female smokers in our study might be due to increasing number of female smokers and higher exposure to biomass fuels by female in our country. This implies that the extensive use of biomass fuels by female individuals increases the risk of exposure to indoor air pollution for long period of time. ${ }^{17}$ Also, another study showed the prevalence of COPD has remained higher in women than in men in United States because of increasing incidence of female smokers than male. ${ }^{20}$ However, a study conducted in India showed a higher number of male affected by COPD which might be due to the higher incidence of male smokers and increased urbanization and air pollution. ${ }^{21}$

The prevalence of COPD patients were found to be increasing with age, reaching a peak in those aged 60-70 years while decrease in those aged older than 70 years. COPD is a slowly progressive disease characterized by airflow limitations and severity of airflow obstruction might be present in elderly patients. ${ }^{22}$ The decreasing rate of COPD after the age of 70 years might be related with the average life expectancy in Nepal, which was proposed to be 68.2 years. ${ }^{23}$ Similar findings were seen in one of the studies. ${ }^{24}$ COPD was found to be less prevalent among patients less than 60 years of age. Similarly, several studies have suggested that patients aged 40-65 years comprise more than half of the total number of COPD patients worldwide. ${ }^{25}$

The present study showed that most patients were smokers and smoking is considered to be one of the risk factors for COPD. ${ }^{26,27}$ This finding correlates with other studies in which cigarette smoking has been established as the most common cause of COPD. ${ }^{26,27}$ However, $8 \%$ of COPD patients were nonsmokers. Although the primary cause of COPD is tobacco smoke, passive smoking also carries serious risks, especially for children and those chronically exposed to smoke. ${ }^{28} \mathrm{WHO}$ also estimates that passive smoking is associated with a 10 to 43 percent increase in risk of COPD in adults. ${ }^{28}$ In addition, another reason for prevalence of COPD among nonsmokers might be due to the use of biomass fuels especially in rural areas. ${ }^{17}$

Further, the present study shows that majority of patients were non-adherent to the prescribed medication. In consistence with this result, a previous study has shown the majority of patients who were non-adherent to the treatment had missed their dose. ${ }^{29}$ In contrary to our findings, another study has revealed a lesser number of patients were non-adherent to the prescribed treatment. ${ }^{30}$ Moreover, though this study has revealed the highest number of male patients was non-adherent to medication regimen, there is not significant relationship between adherence and gender. This result is consistent with the findings from previous studies which have also shown no relation between gender and patient adherence. ${ }^{31-33}$ Nevertheless, differences in adherence pattern between men and women have been reported in the literature, which is suggested to be due to some psychological factors. ${ }^{34}$ The prevalence of anxiety and depression were suggested to be higher in women with COPD, and these psychiatric comorbidities have been independently linked with non-adherence. ${ }^{35,36}$

In addition, our study has shown that non-adherence to the prescribed treatment was seen in later age of the patients. This result was consistent with several other studies which have linked non-adherence to polypharmacy and comorbid diseases. ${ }^{13,31,37}$ Several studies revealed that patients of advanced age were more likely to adhere to prescribed medication but associated complex drug regimen and co-morbid conditions make those patients non-adherent to the prescribed treatment. ${ }^{31,38}$ Moreover, both age and COPD durations are associated with memory loss and cognitive impairment, which adversely affect adherence. ${ }^{39}$ Several researchers reported that patients with COPD are generally of age greater than 60 and are associated with cognitive disabilities which could be the reasons behind non-adherence in such patients. ${ }^{16,40}$

Furthermore, the current study has shown that the most common cause of non-adherence was forgetfulness, which is consistent with the results of several other studies on medication adherence on various chronic diseases along with COPD which have shown that poor adherence is due to forgetfulness and discontinuance of drugs due to side effects. ${ }^{29,41-43}$ Forgetting was related most often with feeling good, interruptions, or changes to normal routine and inconvenience of dosing. ${ }^{43}$ In consistence to previous results, in this study also some patients decided not to take medication because of feeling of wellness. It can be correlated with the tendency of patients to be careless and discontinue the medication when they lack any clinical symptoms in chronic diseases like in a previous study done in diabetic patients. ${ }^{42}$ Lack of clinical symptoms might often be interpreted as disease free by patients resulting on tendency to discontinue the daily medications as suggested by various studies. ${ }^{36,44,45}$ Hence, adherence to treatment regimen can be improved if patients believe that taking medicines daily can improve their quality of life and their functional status.

COPD patients are likely to be on complex oral and inhaler respiratory medications, ${ }^{11,46}$ as well as other prescribed medications, ${ }^{47}$ as most patients are associated with multiple co-morbidities. ${ }^{48}$ Hence, polypharmacy is one of the important precipitating factors of poor adherence. ${ }^{18}$ 
In our study, most patients were on more than two oral medications and majority of such patients showed poor adherence to medication regimen. In agreement to our findings, there are several studies which suggest polypharmacy to be one of the common factors to poor adherence. $^{18,49}$ In addition, researches have also shown that over one-third of patients with COPD were found to use complementary and alternative drugs adding further complexity to their already complex medication regimens. ${ }^{48,50}$ Further, in consistent with our results, another study has also suggested that the lengthier and complicated the treatment regimen is, the greater will be the possibility of non-adherence and simple therapy will inevitably lead to improved patient adherence. ${ }^{51}$

Regarding the route of administration, the present study showed that the majority of patients were on inhalation route and those patients showed adherence to the prescribed treatment. Inhaler forms of medication is preferred over oral doses because of improved breathing, greater self-confidence, and less need to contact health care providers..$^{52}$ However, though patients may adhere to the dosing schedule, they may use the inhaler improperly which might reflect unintentional deviations from treatment regimen. ${ }^{53}$ Among patients who used inhaler forms of medications, our study revealed that those patients who had proper knowledge to use inhaler were more adherent to the prescribed treatment. It has been shown that the lack of proper knowledge or errors in inhalation technique may be associated with additional complexity to inhaled medications. ${ }^{12}$ COPD patients are usually elderly (greater or equals to 60) with multiple comorbidities, as well as impaired physical like hand joint arthritis, ${ }^{12,54}$ and cognitive function, ${ }^{16,41}$ that may interfere with adherence to inhaler and their proper use. Although improper use and underuse often coexist in the same patient, improper use may not correlate with underuse..$^{55}$ Several studies have suggested that the poor inhalation techniques among patients is not surprising when health professionals such as doctors, respiratory therapists, nurses and pharmacists who are involved in educating patients on inhalation techniques, themselves are known to have poor knowledge to use those devices. ${ }^{56,57}$ However, in contrast to our findings, some studies have reported that adherence is higher to oral form of medication than to inhalation form..$^{29,58}$ This could be due to the ease of administrating the drug orally in comparison to inhalation mode of drug administration.

Patient's perception of the disease and drugs also influence the adherence. ${ }^{48}$ Patient's awareness about the possible side effects shared by the doctors and health care professionals are likely to influence the adherence to medications in COPD. ${ }^{48}$ The current study revealed that experiences of side effects and negative perception about their prescribed medications have affected adherence to medications. So, the complexity of drug regimen, concerns for side effects might affect the day-to-day activities, which might be associated with non-adherence in COPD as suggested by other studies. ${ }^{11,16,39}$ Such kind of problems is often encountered in various other chronic diseases like diabetes, ${ }^{42}$ Hypertension, ${ }^{59}$ human immunedeficiency virus-acquired immune-deficiency syndrome (HIV-AIDS), ${ }^{60,61}$ and Tuberculosis as well. ${ }^{62}$

Patient's health beliefs are affected by their health literacy and these beliefs are also contributors to adherence. ${ }^{63}$ Studies have shown that the risk of non-adherence is very high when patients cannot read and understand basic written medical instructions. ${ }^{64}$ Misunderstanding of this type is common. ${ }^{64}$ In agreement to those studies, the current study has shown that majority of non-adherent patients were found to be illiterate. Language barrier might create difficulty in understanding the medical instructions and even if they are able to understand the language of their medical instructions, they cannot comprehend the medical information. ${ }^{65}$ In addition to this, studies have also suggested that the condition is worse if the patient is elderly with cognitive impairments. ${ }^{63,64,66}$

On the other hand, the present study has shown that poor adherence was observed in those patients having less understanding of their illness. They believed that the disease was incurable and had less belief on the prescribed medications. This result is consistent with the findings from another study which suggested that adherence to treatment regimens may be partly affected by patient's understanding of their illness and management options. ${ }^{67}$ Similar results were also shown by other studies in which patients having difficulty in understanding the disease management process showed increased incidence of non-adherence. ${ }^{39,48}$ In addition, our study has shown that patients receiving family/social supports were less adherent to medications than those who were self-concerned about the disease. This might be due to poor understandings of family members about patient's disease and drugs which could be because of low health literacy rates among them. ${ }^{63}$ Similarly, several other studies have suggested that if their family or social group members hold divergent views about their illnesses and treatments, patients might get confused whether or not to adhere to medication leading to higher chances of poor medication adherence. ${ }^{68-71}$ However, other studies have shown that patients who received support from their family members while taking medications had better adherence to medication regimens..$^{58,72}$ So, adherence to medication is not only influenced by the patient's views towards the disease and drugs but also by other people's concern and attitude towards the disease sufficient to influence the patient's belief. ${ }^{58}$ Thus, positive attitude of family members along with patient's self-motivation is essential for improving patient's adherence to medication. Additionally, though affordability of drugs is considered to be one of the barriers to achieving adequate adherence, ${ }^{72,73}$ the present study did not show a significant association with medication affordability. This disparity might be due to the limited sample size with mono-centered study. 


\section{CONCLUSION}

Non-adherence to medication is common problem in COPD. Poor adherence to medication regimen and to other non-drug therapy possess significant barrier to optimum management of COPD. It affects individual's lifestyles and socioeconomic status. In this study forgetting or deciding not to take medication due to concerns of side effects was reported as the most frequent cause of non-adherence. Non-adherence to medication seems to be influenced by various factors like medication and regimen and patients perception of disease and drug. Polypharmacy is found to be one of the major factors that increases non-adherence whereas, proper knowledge of drug administration, patient's knowledge and perception of disease/drugs also affect the patient adherence to the prescribed treatment.

\section{REFERENCES}

1. Mannino, David M, and Victor A Kiri. "Changing the Burden of COPD Mortality." International Journal of Chronic Obstructive Pulmonary Disease 1.3; 2006: 219-33.

2. World Health Organization; Chronic respiratory diseases; 2015. Available at http://www.who.int/respiratory/copd/burden/en/

3. Nepal Health Research Council. Prevalence of Non Communicable Disease in Nepal: Hospital Based Study; Nepal Health Research Council; 2010.

4. Department of Health Services; Ministry of Health and Population, Kathmandu, Nepal: Department of Health Services; 2009. Annual report; p. 10.

5. Rennard SI \& Daughton DM. Cigarette smoking and disease. In: Elias JA, Fishman JA, Grippi MA, Kaiser LR, Senior RM, eds. Pulmonary Diseases and Disorders. New York: McGraw Hill; 1998:697-708.

6. World Health Organization; Chronic Respiratory disease; 2005. Available at http://www.who.int/respiratory/copd/causes/en/ (Accessed on July 2014)

7. Anthonisen NR, Connett JE, Murray RP: Smoking and lung function of Lung Health Study participants after 11 years. The Lung Health Study Research Group. Am J RespirCrit Care Med 2002; 166:675-9.

8. Sutherland ER, Cherniack RM: Management of chronic obstructive pulmonary disease. N Engl J Med 2004; 350:2689-97.

9. Rabe KF, Hurd S, Anzueto A, Barnes PJ, Buist SA, Calverley P et al. "Global Strategy for the Diagnosis, Management, and Prevention of Chronic Obstructive Pulmonary Disease", American Journal of Respiratory and Critical Care Medicine, 2007; 176(6): 532-55.

10. Krigsman K, Moen J, Nilsson JL,Ring L: Refill adherence by the elderly for asthma/chronic obstructive pulmonary disease drugs dispensed over a 10-year period. J ClinPharmTher 2007;32:603-11.

11. Dolce JJ, Crisp C, Manzella B, Richards JM, Hardin JM, Bailey WC. Medication adherence patterns in chronic obstructive pulmonary disease. Chest.1991; 99:837-41.

12. Lareau S \& Yawn B. Improving adherences with inhaler therapy in COPD. Int J Chron Obstruct Pulmon Dis. 2010; 5: 401-6.

13. World Health Organization. Adherence to long-term therapies: policy for action. Meeting report 4-5 June 2001. Available at: http://www. who.int/chronic_conditions/adherence/en/(accessed 12 October 2014). Marinker M, Blenkinsopp A, Bond C, et al. From compliance to concordance: achieving shared goals in medicine taking. London: Royal Pharmaceutical Society of Great Britain.1997.

14. Horne R. Representations of medications and treatment: Advances in theory and measurement. In Petrie KJ, Weinman JA, eds. Perceptions of health and illness. London: Harwood Academic. 1997, p 155-88.
However, there is no association between adherence and various factors like age, sex, literacy, route of administration of drugs, patient's perception, proper knowledge to use inhaler and difficulty using inhaler.

The study shares several limitations as it was mono-centered and was a cross-sectional study. A multi-centered follow-up study might provide a better scenario of adherence related frequent hospitalization.

However, this study provides various evidence regarding adherence pattern and factors influencing it in COPD. Strategies for overcoming non-adherence have to be formulated based on the nature and reasons for nonadherence. Further research to reinforce these issues including health literacy rate is needed in Nepal to improve medication adherence to COPD.

15. Bourbeau J, Bartlett SJ. Patient adherence in COPD; Thorax 2008; 63:831-3.

16. Bhandari R. Sharma R. Epidemiology of chronic obstructive pulmonary disease: a descriptive study in the mid-western region of Nepal. nt $J$ Chron Obstruct Pulmon Dis. 2012; 7: 253-7.

17. Pandey MR. Prevalence of chronic bronchitis in a rural community of the Hill region of Nepal. Thorax. 1984; 39:331-6.

18. Dennis RJ, Maldonado D, Norman S, et al. Wood smoke exposure and risk for obstructive airways disease among women. Chest. 1996;109(Suppl 3): 55S-56S.

19. Akinbami L, Liu X. Chronic Obstructive Pulmonary Disease Among Adults Aged 18 and Over in the United States, 1998-2009. National Center for Health Statistics 2011.

20. Jindal S, Aggarwal A, Chaudhry K, Chhabra S, D'Souza G, Gupta D, et al. A Multicentric Study on Epidemiology of Chronic Obstructive Pulmonary Disease and its Relationship with Tobacco Smoking and Environmental Tobacco Smoke Exposure.Postgraduate Institute of Medical Education and Research, Chandigarh; Indian J Chest Dis Allied Sci 2006; 48: 23-9.

21. Celli BR, MacNee W. ATS/ERS task force. Standards for the diagnosis and treatment of patients with COPD: a summary of the ATS/ERS position paper. Eur Respir J 2004; 23; 932-946

22. World Bank. World Development Indicators. Washington DC: World Bank; 2011.

23. Longmore JM. Oxford Handbook of Clinical Medicine. $8^{\text {th }}$ ed. Oxford, UK: Oxford University Press; 2010.

24. International COPD coalition. COPD Uncovered. 2010. Available from:http://www.internationalcopd.org/documents/COPD_ Uncovered_Report.pdf Accessed on October 2014.

25. Boschetto $P$, Quintavalle S, Miotto D, Cascio N, Zeni E, and Mapp C. Chronic Obstructive Pulmonary Disease (COPD) and occupational exposure. J Occup Med. Toxicol. 2006; 1: 11.

26. Buist AS, Vollmer WM, McBurnie MA. Worldwide burden of COPD in high and low-income countries. Part I. The Burden of Obstructive Lung Disease (BOLD) Initiative. Int. J. Tuberc. Lung Dis. 2008; 12:703-708

27. COPD International. COPD statistics, 2012.

28. James PN, Anderson JB, Prior JG. Patterns of drug taking in patients with chronic airflow obstruction. Postgrad Med J. 1985; 61:7-10.

29. DiMatteo MR, Haskard KB, Williams SL. Health beliefs, disease severity, and patient adherence: A meta-analysis. Med Care. 2007; 45:521-8.

30. Agh T, Inotai A, Mezsaros A. Factors Associated with Medication Adherence in Patients with Chronic Obstructive Pulmonary Disease. Respiration. 2011;82(4):328-34. ISSN 0025-7931f 
31. Apter AJ, Reisine ST, Affleck G, Barrows E, ZuWallack RL. Adherence with twice-daily dosing of inhaled steroids. Socioeconomic and health-belief differences; American Journal of Respiratory and Critical Care Medicine. 1998;157(6) 1810-1817. ISSN 1073-449X

32. Corden ZM, Bosley CM, Rees PJ, Cochrane, GM. Home nebulized therapy for patients with COPD: patient compliance with treatment and its relation to quality of life. Chest. 1997;112(5)1278-82. ISSN 0012-3692.

33. Laforest L, Denis F, Van Ganse E, Ritleng C, Saussier C, Passante N et al. Correlates of adherence to respiratory drugs in COPD patients. Primary Care Respiratory Journal. 2010 June;19(2):148-154. ISSN 1475-1534.

34. Bosley CM, Fosbury JA \& Cochrane GM; The psychological factors associated with poor compliance with treatment in asthma. European Respiratory Journal. 1995;8(6):899-904. ISSN 0903-1936.

35. DiMatteo MR, Lepper HS, Croghan TW. Depression is a risk factor for noncompliance with medical treatment: meta-analysis of the effects of anxiety and depression on patient adherence. Archives of Internal Medicine. 2004;160(14):2101-2107.

36. Rand CS. I took the medicine like you told me, doctor: Self-report of adherence with medical regimens. In: Stone A, ed. The science of selfreport: implications for research and practice. Mahway, NJ: Lawrence Erlbaum Associates, 2000:257-76.

37. Rand CS, Nides M, Cowles MK. Long-term metered-dose inhaler adherence in a clinical trial.The Lung Health Study Research Group. Am J RespirCrit Care Med. 1995;152:580-8.

38. Incalzi RA, Capparella O, Gemma A, et al. The interaction between age and comorbidity contributes to predicting the mortality of geriatric patients in the acute- care hospital. J Intern Med 1997; 242:291-8

39. George J, Kong D and Stewart K;Adherence to disease management programs in patients with COPD.nt J Chron Obstruct Pulmon Dis. Sep 2007; 2(3): 253-262.

40. Ramsey SD: Suboptimal medical therapy in COPD: exploring the causes and concequences. Chest 2000, 117: 33S - 37S

41. Shrestha SS, Shakya R, Karmacharya BM, Thapa P. Medication Adherence to Oral Hypoglycemic Agents Among Type II Diabetic Patients and Their Clinical Outcomes with Special Reference to Fasting Blood Glucose and Glycosylated Hemoglobin Levels. Kathmandu Univ Med J 2013;43(3):226-32.

42. Dolce JJ, Crisp C, Manzella B, Richards JM, Hardin JM, Bailey WC. Medication adherence patterns in chronic obstructive pulmonary disease. Chest. 1991; 99:837-841.

43. Horne R, Weinman J. Patients' beliefs about prescribed medicines and their role in adherence to treatment in chronic physical illness. $J$ Psychosom Res 1999; 47: 555-67.

44. Rapoff MA, Bartlett SJ. Adherence in children and adults. In: Bartlett $\mathrm{SJ}$, ed. Clinical care in the rheumatic diseases. Atlanta: American College of Rheumatology, 2006:279-84

45. Pauwels RA, Buist AS, Calverley PM, Jenkins CR, Hurd SS. Global strategy for the diagnosis, management, and prevention of chronic obstructive pulmonary disease. NHLBI/WHO Global Initiative for Chronic Obstructive Lung Disease (GOLD) workshop summary. Am J RespirCrit Care Med 2001; 163:1256-76.

46. Chryssidis E, Frewin DB, FrithPA;Compliance with aerosol therapy in COPD. NZ Med J. 1981; 250:375-77.

47. George J, Kong DCM, Thoman R, Stewart K: Factors associated with medication non-adherence in patients with COPD. Chest 2005; 128:3198-3204.

48. Restrepo RD, Alvarez MT, Wittnebel LD et al. Medication adherence issues in patients treated for COPD. Int J Chron Obstruct Pulmon Dis. 2008; 3:371-84

49. George J, Ioannides-Demos LL, Santamaria NM et al. Use of complementary and alternative medicines by patients with chronic obstructive pulmonary disease. Med J Aust. 2004; 181:248-51

50. Sackett DL, Haynes RB. Compliance with therapeutic regimens. Baltimore, John Hopkins University Press; 1976.
51. Moore AC, Stone S. Meeting the needs of patients with COPD: patients' preference for the Diskus inhaler compared with the Handihaler. Int J ClinPract. 2004; 58:444-50.

52. McFadden ER. Inhaled aerosol bronchodilators. Baltimore: Williams and Wilkins; 1986.

53. Taffet G, DonohueJ and AltmanP. Considerations for managing chronic obstructive pulmonary disease in the elderly. ClinInterv Aging. 2014; 9: 23-30.

54. Steinman MA, Landefeld CS, Rosenthal GE et al. Polypharmacy and prescribing quality in older people. J Am Geriatr Soc.2006;54: 1516-23.

55. Guidry GG, Brown WD, Stogner SW, et al. Incorrect use of metered dose inhalers by medical personnel. Chest. 1992; 101:31-3.

56. Kesten S, Zive K, Chapman KR. Pharmacist knowledge and ability to use inhaled medication delivery systems. Chest. 1993; 104:1737-42.

57. Tashkin DP. Multiple dose regimens.Impact on compliance. Chest 1995;107(5 Suppl):176S-182182S, ISSN 0012-3692.

58. Svensson S. Medication Adherence, side effects and patient-physician interaction in hypertension. Department of Clinical Pharmacology, Institute of Internal Medicine, The Sahlgrenska Academy at Goteborg University, Sweden. Goteborg 2006; pg no. 43.

59. Enriquez $M$ and Mckinsey D. Strategies to improve HIV treatment adherence in developed countries: clinical management at the individual level. Dove Press Journal.2011;

60. Mandell GL, Bennett JE, Dolin R. Mandell Douglas and Bennett's principles and practice of infectious diseases. $7^{\text {th }}$ ed. Philadelphia, PA: Churchill Livingstone Elsevier. 2009;

61. Amuha MG, Kutyabami P, Kitutu FE, Adome RO and Kalyango JN. Nonadherence to anti-TB drugs among TB/HIV co-infected patients in Mbarara Hospital Uganda: Prevalence and associated factors. African health sciences Afr Health Sci. Aug 1, 2009; 9(Suppl 1): S8-S15

62. Martin LR, Williams SL, Haskard KB and DiMatteo MR. The challenge of patient adherence. Therapeutic and Clinical risk management. Dove press. TherClin Risk Manag. Sep 2005; 1(3): 189-199.

63. Williams MV, Parker RM, Baker DW, et al. Inadequate functional health literacy among patients at two public hospitals. JAMA. 1995; 274:1677-82.

64. Rand CS. Patient adherence with COPD therapy. Eur Respir Rev. 2005; 14:97-101.

65. Schillinger D, Piette J, Grumbach $\mathrm{K}$ et al. Closing the loop: physician communication with diabetic patients who have low health literacy. Arch Intern Med. 2003; 163:83-90.

66. Ray SM, Helmer RS, Stevens A, Franks Andrea, Wallace L., Clinica Utility of the Chronic Obstructive Pulmonary Disease Knowledge Questionnaire. MARCH 2013; 45(3):

67. Greenfield SF, Borkan J, Yodfat Y. Health beliefs and hypertension: a case-control study in a Moroccan Jewish community in Israel. Cult Med Psychiatry. 1987; 11:79-95.

68. Myers RE, Chodak GW, Wolf TA et al. Adherence by African American men to prostate cancer education and early detection. Cancer. 1999; 86:88-104.

69. Soliday E, Hoeksel R. Health beliefs and pediatric emergency department after-care adherence. Ann Behav Med. 2000; 22: 299-306.

70. Straughan PT, Seow A. Attitudes as barriers in breast screening: a prospective study among Singapore women. SocSci Med. 2000; 51:1695-703.

71. Turner J, Wright E, Mendella L, Anthonisen. Preditors of patient adherence to Pressure Breathing. Chest. 1995;108(2):394-400. ISSN 0012-3692.

72. Cramer JA, Bradley-Kennedy C, Scalera A. Treatment persistence and compliance with medications for chronic obstructive pulmonary disease. Canadian Respiratory Journal. 2007;14(1):25-29. ISSN 1198-2241.

73. Jung E, Pickard AS, Salmon JW, Bartle B, Lee TA. Medication adherence and persistence in the last year of life in COPD patients. Respiratory Medicine. 2009;103(4):525-534. ISSN 0954-6111. 